\title{
PENERAPAN GRAFIK PENGENDALIAN DEMERIT TERHADAP DATA KUALITATATIF
}

\author{
Agus Rusgiyono
}

Staf Pengajar PS. Statistika FMIPA UNDIP

\begin{abstract}
Abstraks
A product is represented as inappropriate considered into minor category up to critical, which than given by weight at characteristic of the inappropriate as a according to its importance level. Ploting all amount of inappropriate at one controller graph regardless of type will mislead. To solve it used by graph controller of demerit. Analysis step represent one of the operational step in program operation of quality with a purpose to understand stability and capability of proces wich underway.

Expectation of phase analyse can identify the root problem that caused incidence of variation of quality so that can be continued to repair phase. To understand the stability and capability of process which underway can be depicted with controller graph and analysis its. At this article will be studied demerit graph controller and analysis of capability at data qualitative.
\end{abstract}

Keyword : Stability, Capability and Weighted Graph Controller

\section{Pendahuluan}

Menurut Gaspersz ${ }^{[1]}$ pada dasarnya pengendalian dan peningkatan proses industri mengikuti konsep hidup proses seperti ditunjukkan dalam gambar berikut ini :

\begin{tabular}{|c|c|c|c|}
\hline \multicolumn{2}{|c|}{ Stabilitas } & & \\
\hline Tidak Stabil & Stabil & & \\
\hline & & Tidak Mampu & \\
\hline & & Mampu & \\
\hline
\end{tabular}

Gambar 1. Siklus hidup proses industri

Intepretasi dari siklus hidup proses industri pada Gambar 1 adalah sebagai berikut:

\begin{tabular}{|l|c|c|l|l|}
\hline No. & Stabilitas & Kapabilitas & \multicolumn{1}{c|}{ Situasi } & \multicolumn{1}{c|}{ Analisis } \\
\hline 1. & Tidak & Tidak & $\bullet \begin{array}{l}\text { Keadaan proses di luar } \\
\text { pengendali } \\
\text { Proses akan menghasilkan } \\
\text { produk cacat terus } \\
\text { menerus }\end{array}$ & $\begin{array}{l}\text { Sistem industri berada } \\
\text { dalam kondisi buruk }\end{array}$ \\
\hline 2. & Ya & Tidak & $\begin{array}{l}\text { Keadaan proses dalam } \\
\text { pengendalian } \\
\text { Proses masih } \\
\text { menghasilkan cacat }\end{array}$ & $\begin{array}{l}\text { Sistem industri berada } \\
\text { dalam status } \\
\text { menujunpeningkatan } \\
\text { kualitas global }\end{array}$ \\
\hline
\end{tabular}




\begin{tabular}{|l|c|c|l|l|}
\hline 3. & Ya & Ya & $\begin{array}{l}\text { Keadaan proses dalam } \\
\text { pengendalian } \\
\text { Proses tidak } \\
\text { menghasilkan cacat }\end{array}$ & $\begin{array}{l}\text { Sistem industri berada } \\
\text { dalam kondisi paling } \\
\text { baik }\end{array}$ \\
\hline 4. & Tidak & Ya & $\begin{array}{l}\text { Keadaan proses di luar } \\
\text { pengendalian } \\
\text { Proses menimbulkan } \\
\text { masalah kualitas secara } \\
\text { sporadis }\end{array}$ & $\begin{array}{l}\text { Sistem industri tidak } \\
\text { diperkirakan dan tidak } \\
\text { diinginkan oleh } \\
\text { managemen industri }\end{array}$ \\
\hline
\end{tabular}

Dari tahapan analisis ini diharapkan dapat diidentifikasikan akar masalah yang mungkin menjadi penyebab timbulnya variasi produk yang kemudian dilanjutkan pada tahap perbaikan. Dalam tulisan ini akan dikaji grafik kendali dan kapabilitasnya untuk mengetahui stabilitas dan kapabilitas dari proses pengendalian kualitas yang sedang berlangsung. Dalam hal ini khususnya berlaku bagi data-data kualitatif yang digolongkan dalam dua kategori yaitu sesuai dan tidak sesuai spesifikasi yang telah ditetapkan sebelumnya.

\section{Bahan dan Metode}

Berdasarkan sebuah spesifikasi yang telah ditetapkan sebelumnya, sebuah kualitas produk yang tidak ada pada standar kualitas yang ditetapkan disebut dengan istilah "tidaksesuai". Dalam Mitra ${ }^{[3]}$ juga disebutkan keadaan sebuah produk dengan satu atau lebih ketidaksesuaian yang membuat produk itu tidak berfungsi dinamakan sebagai tak sesuai.

Dalam tulisan ini akan dikaji tipe grafik pengendali:

1. Grafik pengendali atribut yang didasarkan pada tak sesuai, yaitu grafik pengendali proporsi $\mathrm{p}$ (proporsi tak sesuai) dan $n$ (banyaknya produk yang tak sesuai), yang pembentukannya didasarkan pada distribusi Binomial.

2. Grafik pengendali atribut yang didasarkan pada ketaksesuaian yakni grafik pengendali c (frekuensi ketaksesuaian) dan u (frekuensi ketaksesuaian per unit).

3. Grafik pengendali ketaksesuaian yang terboboti atau demirit.

Asas-asas statistik yang melandasi grafik pengendali proses untuk proporsi tak sesuai didasarkan atas distribusi Binomial. Misalkan proses produksi bekerja dalam keadaan stabil, sehingga probabilitas bahwa suatu unit akan tak sesuai dengan spesifikasi adalah $p$ dan unit yang diproduksi berurutan dan independen, maka tiap unit yang diproduksi merupakan realisasi suatu variabel acak Bernoulli dengan parameter $p$.

Apabila sampel acak dengan $\mathrm{n}$ unit produk dipilih, dan $\mathrm{X}$ adalah banyak unit yang tak sesuai maka $\mathrm{X}$ berdistribusi Binomial dengan parameter $\mathrm{n}$ dan $\mathrm{p}$ sehingga :

$$
P\{X=x\}=\left(\begin{array}{l}
n \\
x
\end{array}\right) p^{x}(1-p)^{n-x} \quad, x=0,1,2, \ldots, n
$$

Maka nilai rataan dan varian dari variable random $\mathrm{X}$ adalah $n p$ dan $n p(1-p)$.

Dalam tulisan Kuswadi dan Erna Mutiara ${ }^{[2]}$ telah dibahas langkah pembentukan grafik kendali $p$ dan $n p$ untuk data kuantitatif. Pada tulisan ini menggunakan software SPSS akan dibahas mengenai pembentukan grafik pengendali data demerit untuk data kualitatif. Tinjauan teoritis digunakan untuk mendapatkan bukti matematika terhadap formula yang ada sedangkan untuk mempercepat proses digunakan software SPSS. Data- 
data diambil dari data kualitatif fiktif untuk memperjelas bagaimana proses bekerja dan langkah analisis.

\section{Hasil dan Pembahasan}

Misalkan dalam suatu produk dicatat jumlah produk yang tidak sesuai kualifikasi (X) . Jika Diambil sampel acak sebanyak n, jika $\hat{p}=\frac{\text { frekuensi yang tak sesuai }}{\text { ukuran sampel }}=\frac{X}{n}$.

Karena $\mathrm{X}$ berdistribusi Binomial maka $\hat{p}$ juga berdistribusi Binomial. Sehingga mean dan varian dari $\hat{p}$ dapat dinyatakan dengan :

$$
\begin{aligned}
& \mu_{\hat{p}}=E[\hat{p}]=E\left[\frac{X}{n}\right]=\frac{1}{n} E[X]=p \\
& \sigma_{\hat{p}}^{2}=\operatorname{Var}[\hat{p}]=\operatorname{Var}\left[\frac{X}{n}\right]=\frac{1}{n^{2}} \operatorname{Var}[X]=\frac{p(1-p)}{n}
\end{aligned}
$$

Maka model grafik pengendali $\hat{p}$ adalah:

$$
\begin{aligned}
& \operatorname{UCL} \hat{p}=p+L \sqrt{\frac{p(1-p)}{n}} \\
& \operatorname{CL} \hat{p}=p \\
& \operatorname{LCL} \hat{p}=p-L \sqrt{\frac{p(1-p)}{n}}
\end{aligned}
$$

dengan $\mathrm{L}$ adalah jarak batas-batas pengendali dari garis tengah yang dinyatakan dalam unit deviasi standard.

Bila $\mathrm{p}$ tidak diketahui, maka nilai $\mathrm{p}$ itu harus ditaksir dari data observasi. Jika banyak sampel adalah $\mathrm{m}$ dan $\bar{p}$ adalah rata-rata proporsi tak sesuai maka $\bar{p}$ dihitung dengan cara:

$$
\bar{p}=\frac{\sum_{i=1}^{m} \hat{p}_{i}}{m}=\frac{\sum_{i=1}^{n} x_{i}}{m n}
$$

Dalam hal ini $\bar{p}$ adalah penaksir tak bias dari p. Karena dapat dilihat bahwa:

$$
E[\bar{p}]=E\left[\frac{\sum_{i=1}^{m} \hat{p}_{i}}{m}\right]=\frac{1}{m} \sum_{i=1}^{m} E\left[\hat{p}_{i}\right]=\frac{m p}{m}=p
$$

Sekarang model pengendalian kualitas menjadi:

$$
\begin{aligned}
& \operatorname{UCL} \hat{p}=\bar{p}+L \sqrt{\frac{\bar{p}(1-\bar{p})}{n}} \\
& \text { CL } \hat{p}=\bar{p} \\
& \operatorname{LCL} \hat{p}=\bar{p}-L \sqrt{\frac{\bar{p}(1-\bar{p})}{n}}
\end{aligned}
$$

Bila ukuran sampel tiap pengambilan sampel adalah $n_{i}$ tidak sama maka pengendalian proses didekati dengan dua cara:

\section{Cara 1 :}

nilai $\bar{p}$ dihitung dengan aproximasi : 


$$
\bar{p}=\frac{\sum_{i=1}^{m} \hat{p}_{i}}{m}=\frac{\sum_{i=1}^{m} \frac{x_{i}}{n_{i}}}{m}
$$

dan pengendalian dilakukan pada tiap sampel ke -i:

$$
\begin{aligned}
& \operatorname{UCL} \hat{p}=\bar{p}+L \sqrt{\frac{\bar{p}(1-\bar{p})}{n_{i}}} \\
& \operatorname{CL} \hat{p}=\bar{p} \\
& \operatorname{LCL} \hat{p}=\bar{p}-L \sqrt{\frac{\bar{p}(1-\bar{p})}{n_{i}}}
\end{aligned}
$$

Sebagai contoh hasil olahan data kuatitatif dari pada data dengan level sigma 4,71 menghasilkan grafik pengendali p:

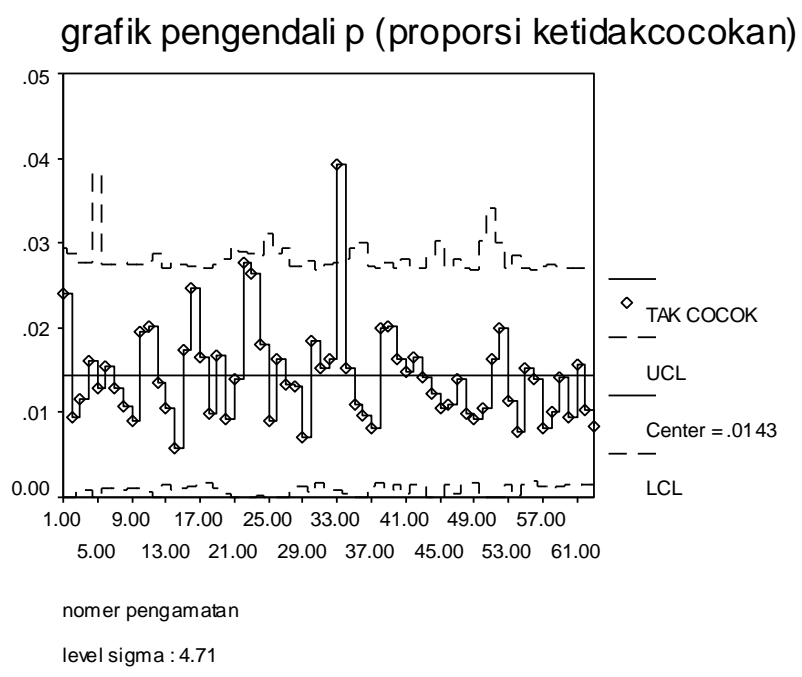

Gambar 2. Grafik pengendali p berdasarkan ukuran sample tiap pengamatan

\section{Cara 2:}

Mendasarkan grafik pengendali pada rata-rata ukuran sampelnya.

Rata-rata ukuran sampelnya dihitung dengan:

$$
\bar{n}=\frac{\sum_{i=1}^{m} n_{i}}{m}
$$

Sedangkan grafik pengendalian prosesnya dirumuskan sebagai berikut:

$$
\begin{aligned}
& \mathrm{UCL} \hat{p}=\bar{p}+L \sqrt{\frac{\bar{p}(1-\bar{p})}{\bar{n}}} \\
& \operatorname{CL} \hat{p}=\bar{p} \\
& \operatorname{LCL} \hat{p}=\bar{p}-L \sqrt{\frac{\bar{p}(1-\bar{p})}{\bar{n}}}
\end{aligned}
$$

Dengan nilai proporsinya rata-rata $(\bar{p})$ :

$$
\bar{p}=\frac{\sum_{i=1}^{m} \hat{p}_{i}}{m}=\frac{\sum_{i=1}^{m} \frac{x_{i}}{\bar{n}}}{m}
$$


Sebagai contoh hasil olahan data kuatitatif dari pada data dengan level sigma 4,71 menghasilkan grafik pengendali p:

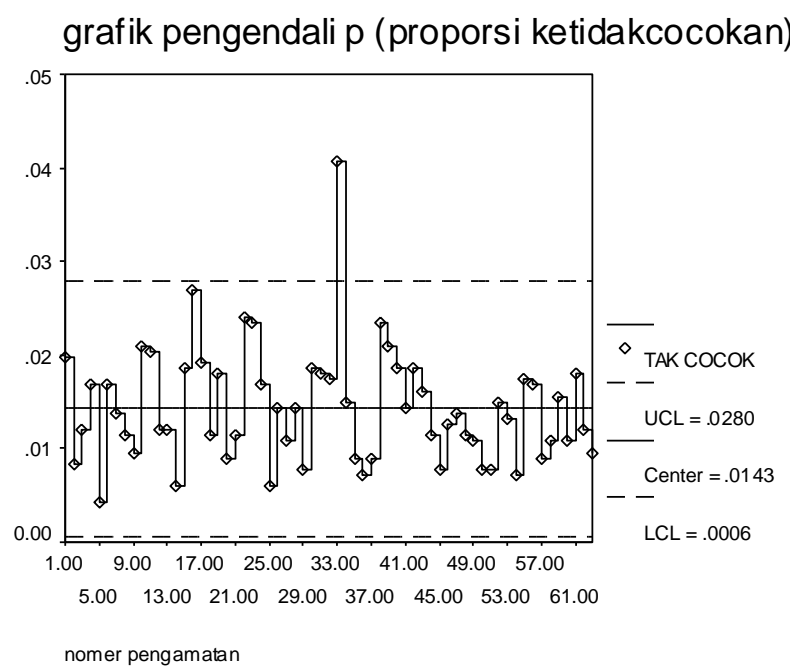

Gambar 3. Grafik pengendali p berdasarkan rata-rata ukuran sampel

\subsection{Grafik Pengendali Demerit}

Suatu produk yang dinyatakan tak sesuai dinyatakan dalam kategori ringan sampai kritis, yang kemudian diberikan pembobotan pada karakteristik ketaksesuaian tersebut sesuai dengan tingkat kepentingannya. Memplotkan semua jumlah ketaksesuaian pada satu grafik pengendali tanpa memperhatikan tipe akan menyesatkan, untuk mengatasinya digunakan grafik pengendali demerit.

Beberapa langkah penggunaan grafik pengendali demerit yakni:

1. Mengklasifikasikan ketaksesuaian dalam tiap klas.

2. Memberikan bobot pada tiap-tiap klas menurut keseriusan ketaksesuaian.

Misalkan terdapat $r$ jumlah klas ketaksesuaian, $c_{j}$ sebagai frekuensi ketaksesuaian klas ke$j$ dalam sebuah sampel maka jumlah ketaksesuaian dari semua klas dalam sebuah sampel $c$ adalah:

$$
c=\sum_{j=1}^{r} c_{j}
$$

$c_{j}$ berdistribusi Poisson $(\lambda)$. Jika ada $m$ sampel dengan ukuran yang sama maka rata-rata jumlah ketaksesuauian dari kklas ke-j dalam $m$ sampel $\left(\bar{c}_{j}\right)$ adalah:

$$
\bar{c}_{j}=\frac{\sum_{i=1}^{m}\left(c_{j}\right)_{i}}{m}
$$

Misalkan $w_{j}$ adalah nilai pembobotan pada klas ke $\mathrm{j}$, maka jumlah demerit ketaksesuaian untuk tiap sampelnya adalah:

$$
c w=\sum_{j=1}^{r} c_{j} w_{j}
$$

Nilai harapan dan varian dari jumlah demerit ketaksesuaian masing-masing adalah 


$$
\begin{aligned}
& \mu_{c w}=E\left[\sum_{j=1}^{r} c_{j} w_{j}\right]=\sum_{j=1}^{r} w_{j} E\left(c_{j}\right)=\sum_{j=1}^{r} w_{j} \bar{c}_{j}=\frac{\sum_{i=1}^{m}(c w)_{i}}{m}=\overline{c w} \\
& \sigma_{c w}^{2}=\operatorname{Var}\left[\sum_{j=1}^{r} c_{j} w_{j}\right]=\sum_{j=1}^{r} w_{j}^{2} \operatorname{Var}\left(c_{j}\right)=\sum_{j=1}^{r} w_{j}^{2} \bar{c}_{j}
\end{aligned}
$$

Sehingga grafik pengendalinya dapat dimodelkan:

$$
\begin{aligned}
& \mathrm{UCL} \mathrm{cw}=\overline{c w}+L \sqrt{w_{j}^{2} \bar{c}_{j}} \\
& \mathrm{CL} \mathrm{cw}=\overline{c w} \\
& \mathrm{LCL} \mathrm{cw}=\overline{c w}-L \sqrt{w_{j}^{2} \bar{c}_{j}}
\end{aligned}
$$

\subsection{Grafik Pengendali Demerit untuk Ketaksesuaian Per Unit}

Jumlah ketaksesuaian per unit dari klas ke- $j$ dalam sampel ke- $i$ dihitung:

$$
u_{i j}=\frac{c_{i j}}{n_{i}}
$$

Dengan $n_{i}$ adalah jumlah unit dalam sampel ke- $i$, maka jumlah demerit untuk ketaksesuaian per unit untuk sebuah sampel adalah:

$$
u w=\sum_{j=1}^{r} w_{j} u_{j}
$$

Rata - rata jumlah ketaksesuaian per unit dari klas ke-j dalam m sampel $\left(\bar{u}_{j}\right)$ adalah:

$$
\bar{u}_{j}=\frac{\sum_{i=1}^{m} c_{i j}}{\sum_{i=1}^{m} n_{i}}=\frac{\sum_{i=1}^{m} n_{i} u_{i j}}{\sum_{i=1}^{m} n_{i}}
$$

Maka nilai rata-rata dan variannya dari demerit untuk ketaksesuaian per unit masingmasing adalah:

$$
\begin{aligned}
& \mu_{u w}=\sum_{j=1}^{r} w_{j} \bar{u}_{j}=\overline{u w} \\
& \sigma_{u w}^{2}=\sum_{j=1}^{r} w_{j}^{2} \bar{u}_{j}
\end{aligned}
$$

Model grafik pengendali $u_{w}$ menjadi:

$$
\begin{aligned}
& \text { UCL uw }=\overline{u w}+L \sqrt{w_{j}^{2} \bar{u}_{j}} \\
& \text { CL uw }=\overline{u w} \\
& \text { LCL uw }=\overline{u w}-L \sqrt{w_{j}^{2} \bar{u}_{j}}
\end{aligned}
$$

Dari hasil pengamatan Gambar 3 diperoleh bahwa keadaan proses yang tidak terkendali akibat data ke 33 yang mungkin akibat kelalaian operator sehingga dengan tidak mengikutsertakan data diluar kendali yakni data ke 33 didapat grafik kendali sebagai berikut: 


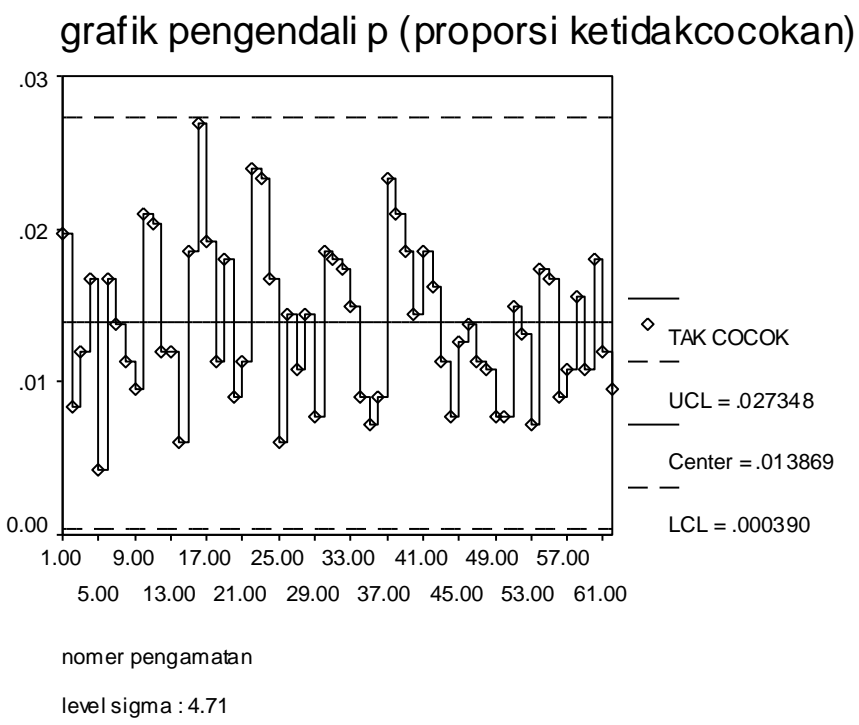

Gambar 4. Grafik pengendali p berdasarkan rata-rata ukuran sample setelah penyesuaian

Sehinga tingkat kapabilitas proses dapat dihitung karena sistem sudah stabil.

\subsection{Fungsi Karakteristik Operasi dan Perhitungan Average Run Length}

Fungsi karakteristik operasi adalah penyajian grafik probabilitas menerima secara salah hipotesis keadaan secara statistik ( yakni kesalahan type II). Kurva karakteristik operasi memberikan ukuran kepekaan grafik pengendali, yakni kemampuannya menyidik suatu pergeseran nilai ( $\bar{p}$ atau $\bar{c}$ ) kesuatu nilai yang diinginkan ( $\mathrm{p}$ atau $\mathrm{c}$ ). Maka probabilitas kesalahan type II adalah:

$$
\begin{aligned}
\beta & =\mathrm{P}[\mathrm{LCL}<\hat{\mathrm{p}}<\mathrm{UCL} \mid \mathrm{p}]=\mathrm{P}[\hat{\mathrm{p}}<\mathrm{UCL} \mid \mathrm{p}]-\mathrm{P}[\hat{\mathrm{p}}<\mathrm{LCL} \mid \mathrm{p}] \\
& =\mathrm{P}[\mathrm{X}<\mathrm{nUCL} \mid \mathrm{p}]-\mathrm{P}[\mathrm{X}<\mathrm{nLCL} \mid \mathrm{p}]
\end{aligned}
$$

Sedangkan grafik pengendali ketaksesuaian dapat dihitung:

$$
\beta=P[L C L<x<U C L \mid c]=P[x<U C L \mid c]-P[x<L C L \mid c]
$$

Dalam merancang grafik pengendali, harus ditentukan ukuran sampel yang digunakan dan frekuensi pengambilan sampel. Suatu cara yang digunakan untuk memutuskan ukuran sampel dan frekuensi pengambilan sampel adalah ARL (Average Run Length) atau rataan panjang giliran dari grafik pengendali. Pada dasarnya ARL adalah banyak titik sampel rata-rata yang harus digambarkan sebelum suatu titik menunjukkan keadaan tak terkendali. ARL dinyatakan sebagai:

$$
\mathrm{ARL}=\frac{1}{P(\text { suatu titik di luar kendali })}
$$

Misalkan $\alpha$ merupakan $\mathrm{P}$ ( suatu titik di luar kendali), maka perumusan untuk ARL dalam keadaan terkontrol adalah:

$$
A R L_{0}=\frac{1}{\alpha}
$$

Sedangkan perumusan untuk ARL dalam keadaan di luar kendali ( $\left.A R L_{1}\right)$ adalah:

$\mathrm{P}($ suatu titik di luar kendali $)=1-\mathrm{P}($ suatu titik dalam kendali $)$

$$
=1-\beta
$$


Sehingga diperoleh:

$$
A R L_{1}=\frac{1}{1-\beta}
$$

\subsection{Kapabilitas Proses}

Peningkatan kapabilitas proses dalam menghasilkan produk menuju tingkat kegagalan nol menunjukkan keberhasilan implementasi program peningkatan kualitas. Kapabilitas proses dapat dihitung dengan langkah sebagai berikut:

1. Menghitung tingkat kegagalan = frekuensi unit yang gagal / frekuensi unit yang diperiksa.

2. Menentukan banyaknya karakteristik kualitas (CTQ) potensial yang mengakibatkan kegagalan.

3. Hitung peluang tingkat kegagalan per karakteristik CTQ = langkah $1 /$ langkah 2 .

4. Hitung kemungkinan kegagalan per satu juta kesempatan $(D P M O)=\operatorname{langkah~} 3 \mathrm{x}$ 1000000 .

5. Mengkonversi nilai DPMO ke dalam tingkat kapabilitas.

Langkah-langkah mengkonversi nilai DPMO ke dalam tingkat kapabilitas ditempuh dengan langkah sebagai berikut:

1. Mengitung $\Phi(Z)=1-\frac{D P M O}{1000000}$, dengan $\Phi(Z)$ distribusi normal baku.

2. Menghitung tingkat kapabilitas $=Z+1,5$.

\section{Kesimpulan}

1. Penentuan stabilitas dapat digambarkan dengan grafik pengendali, yang dihasilkan dari proses yang sedang berlangsung.

2. Untuk mengetahui ukuran dari keandalan proses dapat ditentukan dari perhitungan ARL (Average Run Length) yang didasarkan atas kurva karakteristik operasi dari grafik pengendali

3. Tingkat kapabilitas dapat dinyatakan ke dalam nilai kapabilitas yang dihitung dari nilai DPMO.

4. Penentuan tingkat kapabilitas proses dapat dihitung apabila proses yang sedang berlangsung dalam keadaan stabil.

5. Sasaran keberhasilan suatu program pengendalian dan peningkatan kualitas adalah membawa suatu proses yang memiliki stabilitas dan kapabilitas sehingga mencapai tingkat kegagalan nol

\section{DAFTAR PUSTAKA}

1. Gaspersz, V., 2001, Metode Analisis untuk Peningkatan Kualitas, PT. Gramedia Pustaka Utama, Jakarta.

2. Kuswadi dan Mutiara, E., 2004, DELTA untuk Peningkatan Mutu Berbasis Computer, Elex Media Computindo, Jakarta.

3. Mitra, A., 1993, Fundamentals of Quality Control and Improvement, Macmillan Publishing Company, New York.

4. Pyzdek,T., 2002, The Six sigma Hand Book (Terjemahan), Salemba Empat, Jakarta. 